\title{
D escentralização e alocação de recursos no âmbito do Sistema Único de Saúde (SUS)
}

Decentralization and resource allocation

in the Brazilian $\mathrm{N}$ ational $\mathrm{H}$ ealth System

(Sistema Ú nico de Saúde - SUS)

M aria Alícia U gá 1

Sérgio Francisco Piola 2

Sílvia M arta Porto 1

Solon $M$ agalhães Vianna 2
Abstract This article deals with the decentralization of the Brazilian $\mathrm{N}$ ational $\mathrm{H}$ ealth System (Sistema Ú nico de Saúde - SU S), particularly referred to the distributive resource allocation process among the three government levels. Therefore, it presents, on one hand, the constitutional and legal framework and normative instruments that guide the decentralization process inside the SUS. On the other hand, it analyses the regionalization of the resource allocation that has been effectively done by the $\mathrm{M}$ inistry of $\mathrm{H}$ ealth, including direct expenditures as well as financial transfers to states and municipalities. Finally, general considerations are done.

Key words Brazilian Health System, Decentralization, Resource allocation
Resumo Esteartigo trata da descentralização do SUS, particularmente no que se refere à distribui ção e ao processo de alocação de recursos para a saúde, nas três esferas de governo. Assim, apresenta, por um lado, o marco constitucional elegal desse processo e analisa as $\mathrm{N}$ ormas 0 peracionais que vêm orientando o processo de descentralização no SUS. Por outro lado, aborda a regionalização da alocação de recursos efetivamente executada pelo M inistério da Saúde, incluindo tanto os gastos diretos como os repasses para estados e municípios. Finalmente, são feitas algumas considerações de ordem geral.

Palavras-chave SUS, D escentralização, Alocação de recursos
1 Departamento de Administração e Planejamento em Saúde, ENSP, Fiocruz. Av. Leopoldo Bulhões 1480, 70 andar, M anguinhos, 21041-210, Rio de Janeiro RJ. domingue@ensp.fiocruz.br 2 Instituto de Pesquisas Econômicas Aplicadas. 


\section{Introdução}

A questão do financiamento tem sido um dos maiores desafios no processo de implantação do Sistemaú nico de Saúde (SUS). A despeito de a escassez de recursos ser, por sua natureza, um problema permanente, outras questões de solução mais factível carecem de equacionamento. Entre elas tem particular importância a forma de participação federal no financiamento do SUS, dados o caráter descentralizado do sistema e a hegemonia fiscal da U nião.

Nesse sentido, persiste um contencioso no que se refere à descentralização. Em primeiro lugar pela aparente inapetência do M inistério da Saúde, particularmente nos primeiros anos da década de 1990, em abrir mão de poder. Segundo, porque em um país com a dimensão territorial como a do Brasil, com el evado grau de desigualdades entre regiões e estados e, dentro de um mesmo estado, entre municípios, é, no mínimo, difícil que o processo descentralizador ande com a mesma velocidade em todo o espaço geográfico nacional ou até mesmo que possa ser tratado de maneira uniforme. Além disso, os critérios utilizados para a distribuição dos recursos federais aos estados e aos municípios podem, segundo a maneira em que forem conduzidos, ser insuficientes para diminuir as iniqüidades na alocação dos recursos públicos.

Este artigo trata dessas questões. As duas seções seguintes analisam as $N$ ormas $O$ peracionais que têm orientado o processo de descentralização. A seção "Distribuição regional dos recursos" aborda a regional ização dos recursos do M inistério da Saúde, incluindo tanto os seus gastos diretos como os repasses para estados e municípios. Uma demonstração da utilização de crité rios baseados nas necessidades de saúde é objeto da seção seguinte. Por fim, na última parte são feitas algumas considerações de ordem geral.

\section{Os primeiros passos}

0 processo de descentralização na área da saúde, ainda que tenha ganhado contornos mais definitivos na Constituição de 1988 e na legislação infraconstitucional subseqüente (lei 8.080 de 19 de setembro de 1990, lei 8.142 de 28 de dezembro de 1990, normas e portarias regulamentadoras), é um movimento que começou a se estruturar já ao longo da década de 1980.

Com a institucionalização do Sistema Ú nico de Saúde (SUS), a partir do início dos anos
90, o modelo organizacional do sistema de saúde brasileiro perdeu sua tendência "estadualista" desenhada pelo Sistema Unificado e Descentralizado de Saúde (SUDS), passando a "municipalização" a se constituir o eixo condutor do processo de descentralização do sistema (U gá, 1997). Assim, os municípios foram assumindo o papel de atores estratégicos do SUS, dada sua competência constitucional para prestar, com a cooperação técnica e financeira da U nião e do Estado, servi ços e atendimento à saúde da população (Constituição Federal, art., 30, VII).

Com vistas à cooperação financeira da U nião, a Lei Orgânica da Saúde (lei n. 8.080/90, art. 35) estabeleceu que as transferências federais a estados, Distrito Federal e municípios deveriam ser definidas "segundo análise técnica de programas e projetos" (caput) sendo $50 \%$ do volume desses recursos repassados em base ao tamanho da população ( $(10$ ). E a outra metade a partir da combinação de critérios como perfis epidemiológico e demográfico, capacidade instalada, desempenho técnico, econômico efinanceiro e da previsão do plano qüinqüenal de investimentos. Posteriormente, a lei n. 8.142/90 estabeleceu que as transferências destinadas à cobertura das ações e serviços de saúde pelos entes subnacionais - excluindo expressamente os recursos destinados a investimentos (art. 20, II e III) - seriam regulares e automáticas (arts. 2o, IV e 3o, caput). Segundo a mesma lei, enquanto 0 artigo 35 da lei n. 8.080 não fosse regulamentado, prevaleceria o critério populacional, de forma análoga, portanto, ao Fundo de Participação dos M unicípios (FPM), destinando-se à esfera municipal, pelo menos $70 \%$ desses recursos (lei. n. 8.142/90, art. 30, § 10 e § 20).

A despeito de representarem avanços conceituais importantes no sentido de institucionalizar o processo de descentralização, esses dispositivos legais não vingaram. Esse processo vem sendo regulado por sucessivas N ormas O peracionais (Levcovitz et al., 2001). Um ano depois, a N orma Operacional Básica - SU S N OB 01/91 instituiu, com outra lógica, um sistema de alocação de recursos estruturado em quatro fluxos: 1) o destinado ao financiamento das internações hospitalares, baseado no pagamento direto, por parte do M inistério da Saúde (M S), aos prestadores de serviços, públicos e privados, me diante sistema de pagamento prospectivo por procedimento;

2) o relacionado ao financiamento de assistência ambulatorial, calculado em base per capita (UCA - Unidade de Cobertura Ambulatorial), 
com valores diferenciados entre grupos de estados, multiplicados pelo tamanho da população; 3) o referente aos recursos destinados a investimentos em equipamentos e ampliação das unidades assistenciais já existentes (UCR Unidade de Capacitação da Rede), que variava entre $1 \%$ a $5 \%$ do teto ambulatorial e era inversamente proporcional ao valor da UCA; e 4) o fator de estímulo à municipalização, calculado com base em um valor per capita correspondente a $5 \%$ do valor da UCA, multiplicado pelo tamanho da população, destinado aos municípios que cumprissem os requisitos estabelecidos pela norma.

Evidentemente, os dois primeiros fluxos foram os determinantes na alocação de recursos entre esferas de governo no âmbito do SUS. No que tange à assistência hospitalar estabeleceuse, para cada Estado, uma quota máxima em número de Autorização de Internação H ospitalar (AIH). 0 teto quantitativo anual de internações, correspondente a cada unidade da federação, foi calculado com base na população, tomando-se como parâmetro 0,10 AlH/habitante-ano, ou seja número de habitantes $X 0,10$. Note-se que esse modelo alocativo destinado ao financiamento das internações hospitalares instituiu uma distribuição de recursos determinada meramente pela capacidade instalada e efetivava-se mediante o pagamento direto pelo M S dos serviços prestados por unidades públicas e privadas. Os gestores municipais do SUS só definiam a distribuição das cotas de AIH s entre os diversos hospitais da rede, mas não o tipo de serviço a ser prestado. D essa forma, estados e municípios recebiam, no que diz respeito ao financiamento da assistência hospitalar, somente os recursos referentes aos serviços prestados por intermédio de suas próprias unidades hospitalares.

As atividades ambulatoriais efetuadas por prestadores públicos ou privados, por sua vez, passaram a ser remuneradas de forma similar e a partir do mesmo sistema de informação (SIA) SUS). Entretanto, o total de recursos previsto para cada unidade da federação não poderia superar o teto financeiro definido segundo o número de habitantes e o correspondente valor da Unidade de Cobertura Ambulatorial (UCA). O u seja: teto financeiro ambulatorial = número de habitantes $X$ valor da UCA. Vale observar que, caso existisse saldo positivo entre o volume de recursos faturados e o correspondente teto financeiro municipal, a diferença deveria ser repassada para a esfera estadual de gestão do SUS.
A forma de definiç̧ão dos valores da U CA foi altamente regressiva, tendo em vista que os estados com melhores condições socioeconômicas e sanitárias ficaram com valores per capita da UCA superiores aos demais. Ainda que se reconheça a existência de rel ações entre custo do ato médico, grau de complexidade, qualidade dos serviços e desenvolvimento socioeconômico regional, assim como diferenças regionais na utilização dos serviços, esse sistema de alocação de recursos, longe de diminuir as diferenças, no mínimo, contribuiu para sua consolidação (Porto \& U gá, 1992) e já desconsiderava qualquer tipo de critério tendente a compensar ou diminuir as desigualdades existentes ( $M$ édici, 1991; Rezende, 1992).

A N orma Operacional Básica SU S 01/91 representou, também, um movimento de recentralização do sistema de saúde, tendo em vista que, como apontado em U gá (1991):

a) não implementou o caráter automático das transferências intergovernamentais, na medida que, em vez de transferências globais para estados e municípios, como era esperado, o financiamento da atenção médica se efetivava mediante pagamento direto, por parte do M S aos prestadores de serviços de saúde;

b) reduziu a aten ção à saúde à mera prestação de ações médico-assistenciais, desconsiderando a importância das ações de alcance coletivo; e c) passou a tratar as esferas infranacionais de governo como meros prestadores de serviços médico-hospital ares e ambulatoriais como se atuassem por delegação ministerial e não em consonância com a diretriz constitucional da descentralização.

Assim, a política implementada no governo Collor, através da NOB 01/91, distorceu um dos princípios fundamentais do SUS, ferindo o processo de descentralização que vinha sendo desenvolvido até então.

\section{Avanços a partir de 1993: NOB 01/93 e NOB-SU S 01/96}

Embora os problemas mencionados acima ainda não estejam totalmente superados, sucessivas políticas implementadas a partir de 1993 deram largos passos no sentido de sua superação. A N orma Operacional do Ministério da Saúde N OB 01/93 caminhou em direção ao resgate do processo de descentralização do sistema ao estabelecer três níveis de autonomia de gestão das esferas infranacionais: "incipiente", "par- 
cial" e "semi-plena". N este último, as secretarias estaduais e municipais de saúde, atendido o cumprimento de alguns pré-requisitos, passaram a receber um volume global de recursos para cobertura assistencial e a dispor sobre a sua aplicação.

Outra grande inovação introduzida pela NOB/93, além da transferência de valores globais para 0 atendimento ambulatorial e hospitalar aos municípios em condição de gestão mais avançada (semi-plena), foi o estabelecimento de tetos financeiros para cobertura hospitalar. Expressar em valores financeiros os tetos destinados à assistência hospitalar possibilitou, por um lado, efetuar transferências diretas, fundo a fundo, e, por outro, adotar maior transparência na distribuição de recursos. Assim, sem alterar a quota máxima em número de AlH s de cada Estado, introduziu-se um teto financeiro que não existia na N OB 01/91. Esse teto foi calculado como o produto encontrado entre o número de AlH s e o valor médio histórico da AlHs na unidade federada. Cabe destacar, entretanto, que essa forma de definição dos tetos financeiros perpetuou as distribuições de recursos até então vigentes. No que tange aos recursos destinados à cobertura dos serviços ambulatoriais, a modalidade de alocação incorporada a partir de 1991 não foi alterada.

A NOB 01/93 tentou resgatar paulatinamente o processo de descentralização do SUS, introduzindo estímulos para que estados e municípios fossem adquirindo autonomia na gestão da rede assistencial no seu âmbito de governo. Contudo, em janeiro de 1997, último mês em que vigorou a N OB/96, apenas 144 municípios estavam classificados na categoria de maior autonomia de gestão, para os quais eram efetuados repasses "fundo a fundo". Um entendimento básico então pactuado pela NOB 01/93 foi o de que a descentralização deveria ser um processo lento e gradual, com liberdade de adesão por parte das unidades federadas, e que as instâncias locais de governo, paulatinamente, se habilitariam institucional e tecnicamente a adquirirem maior grau de autonomia de gestão.

A criação, nesse período, das Comissões Intergestores Bipartites e Tripartites foi, sem dúvida, outro grande avanço no sentido da construção de um espaço de concentração das políticas setoriais entre as três esferas de governo, constituindo-se, também, em mecanismo de democratização do processo decisório. Foi nesse espaço de pactuação que foi sendo construída, num demorado mas democrático processo, a Norma O peracional Básica do SUS - NOB-SUS 01/96, aprovada por portaria publicada no Diário Oficial da União de 6 de novembro de 1996.

Esse novo instrumento veio consolidar e aprofundar os avanços no sentido da descentralização do sistema iniciados pela N OB/93. Com a N OB 01/96 as modalidades de gestão de estados e municípios foram reduzidas a duas: gestão plena da atenção básica e gestão plena do sistema, para os municípios; e gestão avançada do sistema e gestão plena do sistema, para os estados. Além, obviamente da situação de "não-habilitado", já existente e aplicável àquelas unidades da federação que não cumprirem os requisitos mínimos de habilitação. A gestão plena do sistema, para além de possibilitar a estados e municípios a governança sobre a prestação de serviços médico-assistenciais, conferiu-Ihes autonomia para gerir o sistema de saúde como um todo, na sua esfera de governo, isto é, todas as ações relativas à promoção, proteção e recuperação da saúde.

Ademais, ela não só representou um ganho na qualidade do processo de descentralização, como, por igual, possibilitou a adoção de modelos de proteção da saúde mais holísticos e menos voltados para apenas a questão da assistência médica. Sea N OB/93 estabeleceu normas e procedimentos reguladores do processo de descentralização da gestão das ações e serviços de saúde, a N OB/96 buscou disciplinar o processo de organização do cuidado à saúde, com o objetivo de induzir um novo modelo de atenção no país.

A base para conformação desse novo modelo sustentar-se-ia nos seguintes pressupostos:

a) atuação centrada na qualidade de vida das pessoas e do meio ambiente, em uma perspectiva intersetorial, baseada na ética do coletivo;

b) integralidade da atenção, incorporando 0 modelo epidemiológico ao modelo clínico dominante;

c) ênfase na relação das equipes de saúde com a comunidade, em especial com as famílias; e

d) utilização de novas tecnologias e processos de informação, educação e comunicação social.

Ainda, a NOB/96 anunciava um salto de qualidade na gestão do sistema a partir de uma concepção ampliada do processo saúde-doença e dos campos de atenção à saúde, estruturando a ação setorial a partir da interação de ações voltadas para o indivíduo e para a coletividade, para 0 atendimento às demandas pessoais eàs exi- 
gências ambientais, articulando a promoção, proteção e recuperação, através de um diálogo intra-setorial e intersetorial permanente.

0 mecanismo essencial para a estruturação do novo modelo consistiu no processo de programação pactuada e integrada entre as três esferas de governo das atividades de assistência ambulatorial e hospitalar, de vigilância sanitária e de epidemiologia e controle de doenças. Esse processo, nomeado desde então como Programação Pactuada Integrada (PPI), visava assegurar a explicitação do pacto entre os gestores; as relações intermunicipais, traduzindo as responsabilidades de cada município na garantia de acesso da população aos serviços de saúde; a reorganização das ações e serviços na lógica do novo modelo de atenção; e a reorganização da gestão do sistema, direcionando a alocação de recursos.

A PPI, segundo a norma, deveria ser elaborada a partir de processo ascendente, de base municipal, configurando as responsabilidades do Estado na busca crescente da eqüidade, da qualidade da atenção e na conformação de uma rede regionalizada e hierarquizada de serviços, com critérios e parâmetros definidos pelas Comissões I ntergestores.

Por uma série de questões, a PPI não se estabeleceu como processo consistente e estruturante do modelo de atenção na vigência da $\mathrm{NOB} / 96$, tendo sido retomada no conjunto de proposições recentes para a regional ização dos serviços consolidadas na norma que regula atualmente o processo de descentralização - a N orma Operacional de Assistência à Saúde 01/ 2001-, que tem no alcance da integralidade e eqüidade e no cuidado à saúde seus principais objetivos.

Pode-se afirmar que a principal estratégia utilizada no âmbito da formulação da N OB/96 para a indução do novo modelo de atenção - e, ao que parece, razoavelmente bem-sucedida em sua implementação - , relaciona-se à estrutura de financiamento adotada para o custeio das ações e serviços de atenção básica de saúde sob gestão municipal, através do Piso de Atenção Básica (PAB), criado pela NOB e regulamentado conforme as portarias GM n. 1.882, de 18/12/97 e GM n. 2.091, de 26 de fevereiro de 1998.

As principais inovações efetivamente implementadas corresponderam:

a) à criação de um valor per capita nacional para o custeio de procedimentos de atenção básica correspondentes aos procedimentos de assistência básica realizados até então no âmbito da assistência médica ambulatorial do sistema (SIA/SUS), isto é, a parte fixa do PAB; e b) à criação de incentivos financeiros para o de senvolvimento de ações no campo mais abrangente da atenção básica, quais sejam: implantação de equipes de saúde da família e de agentes comunitários de saúde, aquisição de medicamentos básicos, ações de nutrição e al imentação a grupos populacionais vulneráveis, ações básicas de fiscalização e controle sanitário de produtos, serviços e ambientes sujeitos à vigilância sanitária, e, ações básicas de diagnóstico, investigação e controle epidemiológico e ambiental de situações de risco e/ou dano para a saúde individual e coletiva, isto é, a parte variável do PAB.

As inovações relacionadas à média e alta complexidade ambulatorial, medicamentose insumos excepcionais (Fração de Assistencial Especializada - FAE, Procedimentos de Alto Custo/Complexidade-APAC), embora tenham representado importante instrumento para 0 registro do atendimento e racionalização do gasto em saúde, não modificaram substantivamente a estrutura de financiamento, na medida em que reproduziram a estrutura tradicional de remuneração por serviços produzidos, exceto para os municípios em gestão plena de sistema que recebiam direta e automaticamente ("fundo a fundo"), nos limites do teto financeiro da assistência para el es estabelecido, os recursos para este campo de provisão do sistema.

Contudo, outras importantes inovações previstas na NOB/96, as quais, sem dúvida, acarretariam modificações qualitativas tanto no modelo de gestão do sistema como no modelo de cuidado à saúde, sequer foram operacionalizadas. É o caso do Índice de Valorização de Resultados (IVR) e do Índice de V alorização do Impacto em Vigilância Sanitária (I visa).

Ademais, esse primeiro momento do processo de descentralização do sistema de saúde brasileiro (período das Normas 01/93 e 01/96) caracterizou-se por um forte viés municipalizante, em que o papel das secretarias estaduais de Saúde foi apenas residual. Além disso, intensificou-se o conflito horizontal entre as municipalidades com o cerceamento de demandas de assistência advindas de municípios vizinhos, instaurando uma tendência de fragmentação do sistema, com comprometimento da solidariedade e do compartilhamento das responsabilidades de gestão (M S/SAS, 2002). Sob a égide da NOB 01/96 (até o início do ano 2000) mais de 4.950 municípios se habilitaram à Gestão Plena da Atenção Básica e 564 municípios à 
Gestão Plena de seus sistemas. No tocante às secretarias estaduais de Saúde, os números são menos significativos: apenas cinco estavam habilitadas à Gestão Plena do sistema estadual (Alagoas, Distrito Federal, Santa Catarina, Pará e Ceará) e cinco à Gestão Avançada do sistema estadual (São Paulo, Bahia, M inas Gerais, Rio Grande do Sul e Paraíba).

A operacionalização da N OB 01/96 introduziu, também, uma excessiva compartimentalização na distribuição de recursos para as esferas infranacionais, que, de certa forma, compromete a autonomia alocativa municipal.

Existem atualmente quatro grandes fluxos de recursos que, por sua vez, estão subdivididos em vários tipos de repasses financeiros. Por outro lado, dentre esses, alguns correspondem a transferências globais de recursos cal culadas em base a um valor per capita, outros constituem-se em incentivos à implementação de programas específicos e outros referem-se ao pagamento por serviços médico-assistenciais prestados pelas unidades pertencentes às efferas infranacionais de governo. Assim, os grandes fluxos de transferências intergovernamentais conformados ao longo da implementação da N OB/96 são: 1) o Piso de Atenção Básica, compreendendo a) uma parte fixa, calculada com base em um valor per capita multiplicado pelo tamanho da população; e b) uma parte variável, destinada ao estímulo financeiro à implementação dos programas: PACS (Programa de Agentes Comunitários) e PSF (Programa de Saúde da Família), PCCN (Programa de Combate às Carências Nutricionais), Ações Básicas de Vigilância Sanitária e Ações Básicas de Vigilância Epidemiológica e Ambiental;

2) os recursos destinados a procedimentos ambulatoriais de al to e médio custo/complexidade, que incluem a) a FAE (Fração Assistencial Especializada), destinada ao financiamento de procedimentos de média complexidade, medicamentos e insumos especiais e órteses e próteses ambulatoriais; b) a APAC, relativa ao financiamento de Procedimentos de Alto Custo/ Complexidade (pagamentos prospectivos por procedimento); ec) o FAEC (Fundo de Ações Estratégicas e Compensação), destinado a compensar os municípios pela realização de procedimentos de alta e média complexidade para pessoas não residentes; este Fundo também envolve os recursos para a municipalização das unidades da Funasa, para o financiamento de medicamentos excepcionais e para a assistência à população indígena;
3) os recursos destinados a A ções de M édia e Alta Complexidade em Vigilância Sanitária (distribuídos segundo valores per capita, conjugadamente a incentivos proporcionais ao volume de arrecadação de taxas de fiscalização);

4) os recursos transferidos sob a forma de pagamentos prospectivos por procedimento (via $\mathrm{AlH}$ - Autorizações para Internação H ospitalar) combinados com fatores de compensação a unidades que atuam com custos hospitalares diferenciados: a) FIDEPS (Fator de Incentivo ao Desenvolvimento de Ensino e Pesquisa), destinado a hospitais de ensino e pesquisa; eb) o IVHE (Índice de Valorização H ospitalar de Emergência).

Esse sistema continua em vigor, mesmo após a aprovação da última norma operacional, a N OAS (N orma O peracional de Assistência à Saúde) aprovada pela portaria GM n. 95 de 26/1/2001. Essa N orma não altera o sistema de alocação de recursos a estados e municípios, tratando fundamental mente da estruturação do processo de regionalização e hierarquização do sistema de saúde e, portanto, da distribuição regional da assistência de alta e média complexidade. N esse sentido, não é obj eto de análise neste artigo.

\section{Distribuição regional dos recursos: situação em 1999}

\section{Considerações gerais}

I dentificar os resultados da política al ocativa do M inistério da Saúdee, a partir daí, (re) definir critérios para os repasses federais para estados e municípios, na busca de maior eqüidade, exige respostas consistentes a diversas indagações, entre as quais destacam-se as seguintes: 1) Que recursos devem ser considerados como sendo destinados às "ações e serviços públicos de saúde", para usar a expressão adotada na Emenda Constitucional (EC) n. 29 que estabelece patamares mínimos de gasto para os três níveis de governo?

2) Qual a parcela dos recursos federais a ser considerada para efeito de distribuição para estados e municípios?

3) Que critérios vêm sendo utilizados para o repasse de recursos federais e quais têm sido os resultados práticos dessa política?

A primeira indagação acima explicitada, de natureza conceitual, decorre da ambigüidade da expressão "ações e serviços públicos de saú- 
de" que não significa, necessariamente, "ações e serviços do SUS", nem se confunde com o orçamento do M inistério da Saúde (MS).

Os estudos sobre o gasto público, em sua maioria, levam em conta apenas o que se encontra nos orçamentos do M inistério da Saúde e das secretarias estaduais e municipais de Saúde. o Conselho Nacional de Saúde, por exemplo, na sua prática de monitoramento mensal do gasto federal com saúde, foca seu olhar apenas sobre os recursos do MS. Essa opção, que possivelmente se reproduz - com as respectivas peculiaridades - nas demais esferas de governo, significa, no âmbito federal, excluir da despesa com saúde, itens como:

1) o gasto do MEC no custeio dos hospitais universitários e de ensino e do programa de saúde escolar, despesas que, por suas características, podem ser consideradas dispêndios com ações e serviços públicos de saúde;

2) os recursos transferidos diretamente pelo M inistério da Fazenda ao Governo do Distrito Federal (GDF) para o custeio da folha de pagamento de funcionários da Secretaria de Saúde; e 3) o gasto do M inistério do Trabalho com higiene e segurança do trabalhador.

A identificação do comportamento do gasto federal com saúde pode ser realizada de duas maneiras: assumindo o gasto do Ministério da Saúde como proxy ou se valendo da metodologia I pea, que incorpora no gasto federal todas as despesas com saúde realizadas por outros órgãos da administração federal, desde que sejam com serviços de saúde de acesso universal egratuito. A opção pela primeira, neste estudo, tem como motivo básico o fato de o valor dos gastos realizados pelo $\mathrm{MS}$, excluídos as despesas com inativos e pensionistas e amortização da dívida, ser o que está sendo considerado pelo Governo Federal para definição do montante mínimo a ser aplicado pela U nião em ações e serviços públicos de saúde, com vistas ao cumprimento do estabelecido na Emenda Constitucional n. 29.

A tabela 1 mostra as diferenças na aplicação das duas metodologias, bem como os resultados obtidos quando se inclui, ou não, no gasto do M inistério da Saúde, os dispêndios com inativos e pensionistas e com amortização da dívida.

\section{Evolução e características do gasto do Ministério da Saúde}

A evolução na última década do gasto federal com saúde, considerando-se somente as disponibilidades líquidas do M S (excluídas as despesas com inativos e pensionistas e serviços da dívida), apresenta quatro características importantes. A primeira diz respeito à mudança do patamar do gasto per capita a partir de 1995, seguida de oscilações nesse indicador a partir de 1996 (Tabela 2). A variação entre o gasto per capita mais baixo (1994) e o mais alto (1997) foi de 33\%. As flutuações na aplicação de recursos nos anos anteriores a 1997 parecem ter sido decisivas para catalisar o movimento político suprapartidário, que gerou a Emenda Constitucional n. 29.

A segunda peculiaridade é a notável mudança - em uma perspectiva de maior prazo no perfil das prioridades da política al ocativa federal. Antes da criação do Sistema Ú nico de Saúde, a maior parte dos recursos assistenciais era destinada ao atendimento hospitalar em

Tabela 1

Brasil: Gasto federal com saúde, segundo distintas óticas de apuração, 1995-2000

Em milhões correntes

\begin{tabular}{lccccc}
\hline Ano & MS(1) & MS(2) & Ipea(3) & \% (1/3) & \%(2/3) \\
\hline 1995 & 14,892 & 12,211 & 13,976 & 6.55 & -12.63 \\
1996 & 14,377 & 12,407 & 13,279 & 8.27 & -6.57 \\
1997 & 18,804 & 15,464 & 17,107 & 9.92 & -9.60 \\
1998 & 19,324 & 15,245 & 16,367 & 18.07 & -6.86 \\
1999 & 20,334 & 18,349 & 18,017 & 12.86 & 1.84 \\
2000 & 22,699 & 20,351 & - & - & - \\
\hline
\end{tabular}

Fonte: M S/SE/ Subsecretraia de Planejamento e Orçamento e I pea/Diretoria de Estudos Sociais

1) Gasto total do MS, sem exclusões

2) Gasto do MS, excluído inativos e pensionistas e dívida

3) Excluídos inativos e pensionistas, dívida, saneamento, alimentação e nutrição

e incluídos H ospitais Universitários e repasses da União 
Tabela 2

Brasil: gasto total e líquido (total e per capita) do M S 1993 - 2000

Em R \$ de dezembro de 2000

\begin{tabular}{lccc}
\hline Ano & Gasto total (em milhões) & \multicolumn{2}{c}{ Líquidol } \\
& & Valor (em milhões) & Per capita $(\mathrm{R} \$ 1,00)$ \\
\hline 1993 & $16,893.28$ & $15,576.21$ & 102.77 \\
1994 & $17,127.48$ & $15,365.65$ & 99.95 \\
1995 & $24,484.35$ & $20,116.29$ & 129.10 \\
1996 & $21,247.31$ & $18,331.28$ & 116.71 \\
1997 & $25,510.11$ & $21,216.88$ & 132.91 \\
1998 & $23,244.26$ & $20,195.71$ & 124.83 \\
1999 & $23,926.78$ & $21,556.12$ & 131.48 \\
2000 & $23,616.44$ & $21,339.72$ & 128.47 \\
\hline
\end{tabular}

Fonte: I pea/Disoc, com base nos dados mensais dos sistemas Siafi/Sidor

1 Desconsiderando despesas com: inativos e pensionistas; amortização, juros e encargos dívida

detrimento da assistência ambulatorial. Atualmente, apenas $43 \%$ da despesa do M S com assistência médica ( $R$ \$10,905 milhões) são destinados às hospitalizações. Embora 0 atual modelo assistencial continue sendo apontado como hospitalocêntrico, a reversão, já alcançada, é expressiva. Cabe ainda destacar que pelo menos $37 \%$ dos recursos ambulatoriais são aplicados em atenção básica de saúde, ou seja, em ações reconhecidamente mais custo-efetivas.

U m terceiro aspecto, tão importante quanto polêmico, se refere ao que se poderia chamar de fatiamento dos repasses do M S para estados e municípios. Ao contrário do que era esperado por muitos formadores de opinião adeptos de um processo mais ortodoxo de descentralização, a cooperação financeira da U nião para estados e municípios de que trata a Constituição (C. F., art, 30, VII) não se expressa em transferências globais de livre uso pela esfera recipiente. $\mathrm{Na}$ verdade, tem prosperado, particularmente a partir da N OB/96, uma enorme variedade de modalidades alocativas, cada uma com critérios próprios.

M as é a quarta característica - a persistência de iniqüidades espaciais na alocação dos recursos financeiros - a que está mais estreitamente ligada ao escopo central deste trabalho.

A segunda questão, mencionada no início deste capítulo, diz respeito à identificação dos recursos federais para saúde passíveis de regionalização. Afinal, nem todo gasto do M inistério da Saúde é regionalizável, levan do à exclusão de recursos que atendem a um dos seguintes requisitos:

1) por não serem considerados gastos em saúde;
2) porque, mesmo sendo, literalmente, gastos com saúde, não devem ser enquadrados como despesa com ações e serviços públicos de saúde no sentido em que essa expressão supostamente assume na EC n. 29 (ações e serviços de acesso universal, igualitário e gratuito);

3) pela impossibilidade de localização espacial da despesa; e,

4) pela característica nacional da ação ou serviço.

No primeiro motivo estaria enquadrado 0 pagamento de inativos e pensionistas e amortização e serviço da dívida. A despesa com aposentadorias e pensões, mesmo sendo realizada pelo Ministério da Saúde, não é, conceitualmente, gasto com saúde, já havendo al gum consenso entre diversos atores envolvidos no debate sobre a regulamentação da EC 29 em torno da exclusão desse item da conta da saúde, e até mesmo dos encargos da dívida, para efeito da fixação do patamar mínimo de recursos a ser aplicado nas três esferas de governo.

No segundo motivo de exclusão como vaIor regionalizável - gasto com saúde não SUS se enquadra a despesa com assistência médica a servidores. M esmo que essa despesa seja, literalmente, um gasto com serviço de saúde, tais serviços não atendem ao princípio do acesso universal, igualitário e gratuito.

0 terceiro motivo - impossibilidade ou dificuldade de localização espacial da despesa se aplica a outros gastos excluídos de regionalização como os pagamentos decorrentes de sentenças judiciais.

Por fim, alguns itens devem ser desconsiderados por se referirem a ações federais típicas 
como, por exemplo, o pagamento de contribuições decorrentes da participação do Brasil em organismos internacionais ou por se enquadrarem como ações e serviços de natureza coletiva e alcance nacional como os de responsabilidade da Fundação Osvaldo Cruz (Fiocruz), da Agência N acional de Saúde Suplementar (ANSS), Agência Nacional de Vigilância Sanitária (Anvisa) e o gasto com processamento de dados.

A partir dessas restrições os valores regionalizados utilizados neste trabal ho al cançam 0 valor de $\mathrm{R} \$ 16.370,9$ milhões, ou seja, o equivalente a $80,5 \%$ do gasto total (bruto) do M S em 1999 ( $R \$ 20.334$ milhões), ou $89,2 \%$ do gasto líquido ( $R \$ 18.349,5$ milhões).

\section{Fontes de informação}

O Sistema de Acompanhamento Financeiro (Siafi) e o Sistema Integrado de D ados Orçamentários (Sidor) do governo federal foram as fontes básicas para identificação dos gastos federais com saúde, uma vez que englobam tanto os dispên dios realizados pela administração direta como pela indireta.

A partir dessa base pode-se identificar os gastos diretos com pessoal, outras despesas correntes, investimentos e outras despesas de capital, além das transferências voluntárias para níveis subnacionais de governo e para instituições privadas.

Contudo, a regionalização dos dispêndios federais com saúde com base no Siafi/Sidor não é completa, uma vez que boa parte dos projetos/atividades no campo da saúde não apresenta a destinação geográfica inequívoca. Sendo assim, se fez necessário recorrer a outras fontes de informação. A principal delas, o banco de dados do Datasus, permitiu, entre outros aspectos, localizar dispêndios com pagamentos a provedores, feitos diretamente pelo ministério e com repasses para estados e municípios destinados ao custeio de tratamentos ambulatoriais e hospitalares e atenção básica (PAB fixo e PAB variável).

Para a regionalização segundo a natureza da despesa considerou-se neste estudo, apenas dois grandes agregados: custeio (destaque para gasto com pessoal) e capital. Isto porque a principal finalidade da regionalização da despesa é, em essência, a identificação das desigualdades nas políticas alocativas o que dispensa maior detaIhamento por categoria econômica.

\section{Principais resultados}

Para analisar a regional ização do gasto do M inistério da Saúde as ações e programas foram apartados neste estudo em três grandes grupos:

1) Assistência ambulatorial e hospitalar;

2) Programas selecionados; e

3) Outras despesas

\section{- Assistência ambulatorial e hospitalar}

As despesas deste grupo incluem os gastos com internações e com atendimento ambulatorial, sendo que neste último subgrupo foram computadas as despesas ambulatoriais de média e alta complexidade e com serviços de atenção básica à saúde.

As despesas com atenção hospitalar e ambulatorial atingiram em 1999 o montante de $\mathrm{R} \$ 10.905$ milhões, sendo $\mathrm{R} \$ 4.733,4$ milhões $(43,4 \%)$ com assistência hospitalar e R $\$ 6.171,6$ milhões $(56,6 \%)$ com atendimento ambulatorial $(R \$ 3.843,4$ milhões com atendimento ambulatorial de média e al ta complexidade e $\mathrm{R} \$ 2.328,2$ com atenção básica de saúde).

$\mathrm{N}$ a distribuição per capita da despesa total com assistência ambulatorial e hospitalar as regiões mais beneficiadas são Sudeste $(R \$ 72,30)$ e Sul $(R \$ 70,05)$, com valores $8,7 \%$ e $5,3 \%$ acima da média nacional $(\mathrm{R} \$ 66,52)$. A região $\mathrm{N}$ orteé menos beneficiada com um per capita $24,5 \%$ inferior à média do país (Tabela 3).

a) Atenção básica

As despesas com atenção básica são atendidas com recursos do Piso Assistencial Básico (PAB fixo) acrescidos dos incentivos (PAB variável), que custeiam atividades no campo das vigilâncias Sanitária, Ambiental eEpidemiológica, Farmácia Básica, Programas de Agentes C omunitários da Saúde e Saúde da Família (PACS/ PSF), Combate à Carências N utricionais, Saúde Indígena e M edicamentos para Saúde M ental.

A despesa com atenção básica totalizou $\mathrm{R} \$ 2,328$ milhões em 1999, cerca de $37 \%$ do gasto de toda atenção ambulatorial ou quase $50 \%$ da despesa com assi stência hospitalar. Do total da despesa com atenção básica, $R$ \$1.694 milhão $(72,7 \%)$ foi destinado ao PAB fixo e o restante aos incentivos do PAB variável.

0 per capita médio nacional para Atenção Básica foi de R\$14,20 em 1999 (Tabela 4). A distribuição inter-regional dos recursos destinados à Aten ção Básica é bastante eqüitativa. N ordeste e N orte, macrorregiões mais pobres, apresen- 
Tabela 3

Gasto per capita regionalizado do M S por região/Estado, segundo itens de despesa selecionados - 1999

\begin{tabular}{|c|c|c|c|c|c|c|c|c|c|}
\hline Região e UF & $\begin{array}{l}\text { Pessoal } \\
\text { ativo1 }\end{array}$ & $\begin{array}{l}\text { Assistência } \\
\text { ambulatorial } \\
\text { e hospitalar2 }\end{array}$ & Rede MS3 & $\begin{array}{l}\text { Programas } \\
\text { do FNS4 }\end{array}$ & $\begin{array}{l}\text { Medicamentos } \\
\text { estratégicose } \\
\text { excepcionais5 }\end{array}$ & $\begin{array}{l}\text { Investimen- } \\
\text { tos (FNS) }\end{array}$ & $\begin{array}{l}\text { Funasa } \\
\text { Controle de } \\
\text { endemia }\end{array}$ & $\begin{array}{l}\text { Funasa } \\
\text { Saneamento } \\
\text { básico }\end{array}$ & Total \\
\hline Norte & 20,09 & 50,18 & 0,43 & 3,64 & 2,40 & 3,56 & 4,91 & 7,42 & 92,63 \\
\hline Rondônia & 35,93 & 55,28 & - & 3,84 & 1,61 & 3,02 & 7,47 & 9,53 & 116,68 \\
\hline Acre & 21,57 & 49,93 & - & 3,72 & 2,48 & 4,57 & 11,24 & 51,38 & 144,90 \\
\hline Amazonas & 15,00 & 45,57 & - & 2,76 & 3,23 & 3,09 & 5,18 & 4,17 & 79,0 \\
\hline Roraima & 46,45 & 44,12 & - & 24,53 & 1,80 & 9,11 & 16,97 & 73,57 & 216,55 \\
\hline Pará & 17,45 & 49,19 & 0,89 & 2,53 & 1,88 & 3,04 & 3,00 & 0,97 & 78,95 \\
\hline Amapá & 25,66 & 44,22 & - & 12,96 & 2,09 & 8,05 & 9,08 & 11,87 & 113,93 \\
\hline Tocantins & 18,18 & 63,83 & - & 2,67 & 4,33 & 4,47 & 3,84 & 8,11 & 105,43 \\
\hline Nordeste & 14,88 & 61,75 & 0,14 & 2,55 & 2,51 & 2,51 & 2,47 & 2,54 & 89,35 \\
\hline M aranhão & 18,85 & 58,62 & - & 2,02 & 1,14 & 1,48 & 2,12 & 2,87 & 87,10 \\
\hline Piauí & 12,92 & 66,99 & - & 1,88 & 1,89 & 2,67 & 2,91 & 1,48 & 90,74 \\
\hline Ceará & 14,88 & 67,90 & 0,92 & 2,17 & 3,84 & 2,31 & 2,38 & 3,17 & 97,57 \\
\hline $\begin{array}{l}\text { Rio Grande } \\
\text { do N orte }\end{array}$ & 15,40 & 61,67 & - & 3,50 & 3,16 & 2,84 & 3,97 & 8,86 & 99,40 \\
\hline Paraíba & 19,45 & 58,28 & - & 4,31 & 2,47 & 4,72 & 2,89 & 3,44 & 95,56 \\
\hline Pernambuco & 15,25 & 67,50 & - & 3,02 & 3,68 & 2,00 & 1,89 & 1,46 & 94,80 \\
\hline Alagoas & 14,74 & 61,65 & - & 2,46 & 2,61 & 2,31 & 2,99 & 5,48 & 92,24 \\
\hline Sergipe & 16,90 & 61,50 & - & 3,52 & 2,46 & 1,99 & 4,59 & 2,65 & 93,61 \\
\hline Bahia & 11,91 & 56,20 & - & 2,09 & 1,65 & 2,78 & 2,10 & 0,76 & 77,49 \\
\hline Sudeste & 16,03 & 72,30 & 5,17 & 2,96 & 7,04 & 2,31 & 1,39 & 1,01 & 108,21 \\
\hline M inas Gerais & 7,67 & 63,06 & - & 2,68 & 3,41 & 1,52 & 0,97 & 1,55 & 80,86 \\
\hline Espírito Santo & 9,93 & 58,23 & - & 2,17 & 4,26 & 2,78 & 1,79 & 8,70 & 87,86 \\
\hline Rio deJaneiro & 57,35 & 70,60 & 26,14 & 4,59 & 9,29 & 4,14 & 3,99 & 1,21 & 177,31 \\
\hline São Paulo & 4,65 & 78,57 & - & 2,53 & 8,15 & 1,95 & 0,55 & 0,03 & 96,43 \\
\hline Sul & 9,83 & 70,05 & 9,45 & 2,61 & 4,92 & 1,55 & 0,44 & 0,51 & 99,36 \\
\hline Paraná & 4,31 & 71,53 & - & 4,19 & 4,57 & 1,21 & 0,52 & 0,50 & 86,83 \\
\hline Santa Catarina & 7,05 & 65,29 & - & 1,38 & 5,52 & 1,83 & 0,41 & 1,11 & 82,59 \\
\hline $\begin{array}{l}\text { Rio Grande } \\
\text { do Sul }\end{array}$ & 16,44 & 71,09 & 23,16 & 1,74 & 4,93 & 1,71 & 0,37 & 0,21 & 119,65 \\
\hline Centro-Oeste & 18,50 & 60,15 & - & 4,69 & 3,75 & 3,21 & 6,88 & 3,00 & 100,18 \\
\hline $\begin{array}{l}\text { M ato Grosso } \\
\text { do Sul }\end{array}$ & 12,87 & 57,59 & - & 5,82 & 5,09 & 2,29 & 3,72 & 3,05 & 90,43 \\
\hline M ato Grosso & 10,88 & 61,59 & - & 3,47 & 3,27 & 3,85 & 4,13 & 8,58 & 95,77 \\
\hline Goiás & 12,19 & 57,78 & - & 3,28 & 2,47 & 2,72 & 2,43 & 1,30 & 82,17 \\
\hline Distrito Federal & 49,01 & 66,90 & - & 8,46 & 6,11 & 4,60 & 24,39 & 0,40 & 159,87 \\
\hline Brasil & 15,25 & 66,52 & 3,68 & 2,96 & 4,87 & 2,41 & 2,19 & 1,98 & 99,86 \\
\hline
\end{tabular}

Fonte: MS (Subsecretaria de Planejamento e Orçamento); Siafi (para os dados de pessoal apurados por M aria Alice Fernandes) e Datasus. Elaboração dos autores.

1 Estimativa baseada na distribuição do gasto federal com pessoal de saúde levantado por $M$ aria Alice Fernandes

2 Inclui Atenção Básica (PAB fixo, PSF, PACS, Vigilância Sanitária, PCCN, Funasa, Farmácia Básica, M edicina,

Saúde M ental e Assistência, População Indígena)

$3 \mathrm{~N}$ ão inclui rede Sarah e Rede Funasa

4 Inclui erradicação Aedes Aegypti/dengue, sangue e hemodiálise; prevenção do câncer cervicouterino:

Emendas Parlamentares e AIDS (exclusive medicamento)

5 Estratégicos: utilizados para o tratamento de doenças de perfil endêmico (tuberculose, hanseníase, aids, leishmaniose,

malária, esquistossomose, filariose, tracoma, peste, diabete e hemofilia). Excepcionais: medicamentos de alto custo

e uso prolongado para tratamento de doenças neurológicas, auto-imunes, osteoporose e transplante 
Tabela 4

Brasil - despesas per capita do M inistério da Saúde com atenção hospitalar e ambulatorial, por estado e região, 1999

Em $\mathrm{R} \$ 1,00$

\begin{tabular}{|c|c|c|c|c|c|}
\hline \multirow[t]{2}{*}{ Região e UF } & \multirow{2}{*}{$\begin{array}{c}\text { Assistência } \\
\text { hospitalar }\end{array}$} & \multicolumn{3}{|c|}{ Assistência ambulatorial } & \multirow[t]{2}{*}{ Total } \\
\hline & & $\mathrm{MACl}$ & Atenção Básica2 & Sub-Total & \\
\hline Norte & 18,77 & 15,26 & 16,15 & 31,41 & 50,18 \\
\hline Rondônia & 19,45 & 18,86 & 16,96 & 35,82 & 55,27 \\
\hline Acre & 19,74 & 16,24 & 13,96 & 30,20 & 49,94 \\
\hline Amazonas & 13,25 & 19,32 & 13,00 & 32,32 & 45,57 \\
\hline Roraima & 12,86 & 18,25 & 13,02 & 31,27 & 44,13 \\
\hline Pará & 20,48 & 11,76 & 16,96 & 28,72 & 49,20 \\
\hline Amapá & 12,04 & 17,42 & 14,76 & 32,18 & 44,22 \\
\hline Tocantins & 25,21 & 18,12 & 20,50 & 38,62 & 63,83 \\
\hline Nordeste & 24,36 & 20,18 & 17,21 & 37,39 & 61,75 \\
\hline M aranhão & 20,06 & 22,63 & 15,92 & 38,55 & 58,61 \\
\hline Piauí & 28,29 & 19,62 & 19,07 & 38,69 & 66,98 \\
\hline Ceará & 25,52 & 23,02 & 19,35 & 42,37 & 67,89 \\
\hline Rio Grande do N orte & 21,85 & 23,04 & 16,78 & 39,82 & 61,67 \\
\hline Paraíba & 25,32 & 16,49 & 16,46 & 32,95 & 58,27 \\
\hline Pernambuco & 27,97 & 21,60 & 17,93 & 39,53 & 67,50 \\
\hline Alagoas & 23,19 & 18,67 & 19,78 & 38,45 & 61,64 \\
\hline Sergipe & 21,54 & 20,65 & 19,31 & 39,96 & 61,50 \\
\hline Bahia & 23,46 & 17,52 & 15,22 & 32,74 & 56,20 \\
\hline Sudeste & 31,08 & 29,01 & 12,21 & 41,22 & 72,30 \\
\hline M inas Gerais & 28,44 & 19,85 & 14,77 & 34,62 & 63,06 \\
\hline Espírito Santo & 24,20 & 21,75 & 12,28 & 34,03 & 58,23 \\
\hline Rio de Janeiro & 30,21 & 28,46 & 11,94 & 40,40 & 70,61 \\
\hline São Paulo & 33,25 & 34,25 & 11,07 & 45,32 & 78,57 \\
\hline Sul & 36,36 & 20,33 & 13,35 & 33,68 & 70,04 \\
\hline Paraná & 38,51 & 17,95 & 15,07 & 33,02 & 71,53 \\
\hline Santa Catarina & 27,47 & 24,88 & 12,95 & 37,83 & 65,30 \\
\hline Rio Grande do Sul & 38,89 & 20,25 & 11,95 & 32,20 & 71,09 \\
\hline Centro-0este & 28,35 & 17,85 & 13,95 & 31,80 & 60,15 \\
\hline M ato Grosso do Sul & 31,31 & 12,87 & 13,41 & 26,28 & 57,59 \\
\hline M ato Grosso & 24,42 & 21,82 & 15,34 & 37,16 & 61,58 \\
\hline Goiás & 27,26 & 16,69 & 13,84 & 30,53 & 57,79 \\
\hline Distrito Federal & 32,72 & 21,08 & 13,10 & 34,18 & 66,90 \\
\hline Brasil & 28,87 & 23,44 & 14,20 & 37,64 & 66,51 \\
\hline
\end{tabular}

Fonte: M S/Datasus (Internet). Elaboração dos autores

1 M édia e alta complexidade ambulatorial, não inclui assistência hospitalar

2 PAB fixo e incentivos ( PACS/PSS, PCCN, etc.) 
tam valores per capita expressivamente superiores as demais, $R \$ 17,21$ e $R \$ 16,15$, respectivamente. A diferença entre $N$ ordeste $(R \$ 17,21)$ e Sudeste $(R \$ 12,21)$ é superior a $40 \%$. Dezesseis estados receberam um per capita para atenção básica acima da média nacional: todos os estados do N ordeste, quatro da região N orte (Rondônia, Pará, Amapá eTocantins) e apenas três ( $M$ ato Grosso, Paraná e M inas Gerais) das demais regiões.

b) Atenção Ambulatorial de M édia e Alta Complexidade

A atenção ambulatorial dealta e média complexidade realizou em 1999 um dispêndio de $\mathrm{R} \$ 3.843$ milhões, $65 \%$ superior ao da atenção básica ( $R$ \$2.328 milhões) e equivalente a $35 \%$ do gasto assistencial total ( $R \$ 10.905$ milhões).

Do ponto de vista redistributivo, a atenção ambulatorial de alta e média complexidade teve, em 1999, um comportamento praticamente inverso ao da atenção básica (Tabela 4). Fortemente condicionados pela distribuição espacial da oferta, os dispêndios federais (per capita) com atenção ambulatorial de média e alta complexidade são expressivamente mais altos na região Sudeste $(R \$ 29,01)$ do que nas demais (N orte, $R \$ 15,26$; N ordeste, $R \$ 20,18$; Centro-O este, $R \$ 17,85$ e Sul, $R \$ 20,33)$. A região Sudeste é a única com per capita bem superior $(23,8 \%)$ à média nacional $(R \$ 23,44)$.

Entre os estados o caráter concentrador da despesa se mantém. Apenas São Paulo ( $R$ \$ $34,25)$, Rio de Janeiro $(R \$ 28,46)$ e Santa $C a-$ tarina $(R \$ 24,88)$ superaram a média nacional. N enhum Estado do N orte e do Nordeste alcançou a média nacional. A penas Ceará ( $R$ \$ $23,02)$ e Rio Grande do N orte $(R \$ 23,04)$ chegaram perto. $\mathrm{N}$ a região N orte, o Pará situouse quase $50 \%$ abaixo do per capita nacional.

c) Assistência Hospitalar

Em 1999 a despesa com assistência hospitalar foi de $\mathrm{R} \$ 3.943$ milhões, ou seja, um per capita nacional médio de $R \$ 28,87$ (Tabela 4). Do ponto vista inter-regional o per capita mais alto foi o da região Sul $(R \$ 36,36)$ e os mais baixos foram os das regiões $N$ orte $(R \$ 18,77)$ e $N$ ordeste $(R \$ 24,36)$.

As desigual dades observadas na assistência ambulatorial de al ta e média complexidade se configuram menos expressivas do que no campo da atenção hospitalar quando visto sob a ótica da Razão entre Valores Extremos. Enquanto no primeiro caso a Razão entre o per capita mais alto (São Paulo, R\$34,25) e o mais baixo ( $M$ ato Grosso do Sul, R\$12,87) é de 2,66 , no se- gundo (atenção hospitalar) a Razão é 3,22 onde o per capita mais alto está no sul (Rio Grande do Sul, $R \$ 38,89$ ) e o mais baixo no norte (Amapá, $R \$ 12,04)$.

Por outro lado, os seis estados com per capita acima da média nacional estão nas regiões Sudeste (SP e RJ), Sul (PR e RS) e Centro-Oeste (MS e DF). Por exclusão todos os estados do Norte e N ordeste estão abaixo da média sendo que em três (AM, RR e AP) os per capita correspondem a menos de $50 \%$ do valor médio nacional.

\section{- Programas selecionados}

N este grupo foram consolidadas as despesas com Assistência Farmacêutica ( $R$ \$798,9 miIhões), Controle de Endemias ( $R \$ 358,4 \mathrm{mi}$ Ihões), Saneamento Básico (R $\$ 323,9$ milhões) e alguns programas do Fundo Nacional de Saúde (doenças transmissíveis, sangue e hemoderivados, câncer cérvico uterino, Aids e emendas parlamentares num total de $\mathrm{R} \$ 485,3$ milhões).

a) Assistência Farmacêutica

Os recursos despendidos com medicamentos excepcionais e estratégicos atingiram o montante de R $\$ 798,9$ milhões em 1999. 0 total do gasto com assistência farmacêutica seria, na verdade, maior se incluídos os medicamentos destinados à farmácia básica e para saúde mental que foram computados na despesa com Atenção Básica e os medicamentos usados nas internações, incluídos na assistência hospitalar. Assim, considerando-se apenas os medicamentos estratégicos e excepcionais, nota-se grandes diferenças inter-regionais e interestaduais na alocação desses recursos. A região Sudeste tem um per capita de $R \$ 7,04$ ( $44,5 \%$ acima da média nacional, que foi de $R \$ 4,87)$ e a região Sul $(R \$ 4,92)$ quase iguala essa média do país. Todas as demais, principalmente $\mathrm{N}$ orte $(\mathrm{R} \$ 2,40)$ e N ordeste $(R \$ 2,51)$, estão bem abaixo da média.

As diferenças aumentam na distribuição entre estados. 0 per capita do Rio de Janeiro $(R \$ 9,29)$ é oito vezes superior ao do $M$ aranhão $(R \$ 1,14)$, o menor do país. Vinte e um estados estão abaixo da média nacional, o que inclui todo $0 \mathrm{~N}$ ordeste e $\mathrm{N}$ orte. $\mathrm{N}$ as demais regiões apenas MT, GO, PR, ES e M G estão na mesma si tuação dos estados do N orte e N ordeste.

U ma parte da desigualdade pode ser explicada pela distribuição dos medicamentos para Aids cuja alocação está concentrada na região Sudeste, especialmente nos estados de São Paulo e do Rio de Janeiro. Contudo, como esses re- 
cursos são distribuídos de forma proporcional ao número de doentes, vale dizer considerando necessidades objetivas específicas, a alocação desigual conforma uma política nitidamente ancorada no princípio da eqüidade, desde que desconsiderando a possibilidade de contrapartida de cada estado (Tabela 5).

b) Programas a Cargo do Fundo $\mathrm{N}$ acional de Saúde

No âmbito do Fundo N acional de Saúdeforam regionalizados $R \$ 561,6$ milhões, correspondendo aos recursos alocados para controle de al gumas doenças transmissíveis ( $R \$ 186,2$ milhões), câncer cérvico uterino ( $\mathrm{R} \$ 46,8 \mathrm{mi}$ Ihões) e Aids, com exclusão de medicamentos, ( $R \$ 106,5$ milhões), aos quais foram agregados os montantes destinados ao programa de sangue e hemoderivados ( $R \$ 34,7$ milhões) e emendas parlamentares ( $R \$ 187,4$ milhões). As emendas parlamentares e o controle de doenças transmissíveis respondem por $66 \%$ dos recursos.

Duas regiões estão, em valores per capita, abaixo da média nacional que corresponde a $R \$ 2,96$ : Nordeste $(R \$ 2,55)$ e Sul $(R \$ 2,61)$. As re giões Centro-O este $(R \$ 4,69)$ e N orte $(R \$ 3,64)$ apresentam os valores per capita mais altos (Tabela 5).

0 per capita de Roraima ( $R \$ 24,53)$ é o mais alto do país e cerca de 7 vezes maior que a mé dia nacional. Os outros dois estados com os mais al tos per capita são Amapá ( $R \$ 12,96)$ e Distrito Federal $(R \$ 8,46)$.

C) Controle de Endemias

No controle de endemias sob a responsabilidade da Funasa os recursos regionalizados atingiram o valor de $R \$ 358,4$ milhões, dos quais $32,7 \%$ foram aplicados no combate ao aedes egyipti.

A distribuição desses recursos não é comparável às anteriores dada a natureza das aplicações. Como são recursos para controle de endemias é óbvio que sejam utilizados onde essas doenças estão mais presentes. Por isto os per capita do Sul $(R \$ 0,44)$ e Sudeste $(R \$ 1,39)$ são os mais baixos. Seriam ainda menores não fora a reintrodução do aedes incorporando a dengue e o risco da febre amarela entre os problemas de saúde pública dessas duas regiões. Os mais altos per capita para o controle de endemias são encontrados nas regiões CentroOeste $(R \$ 6,88)$ e N orte $(R \$ 4,91)$. 0 valor da re gião Centro-O este, contudo, deve ser visto com cautela pois, possivel mente, incorpora despesas cuja regionalização não foi identificada (Tabela 5). b) Saneamento Básico

Perto de $66 \%$ dos recursos destinados a saneamento básico ( $R \$ 323,9$ milhões) financiaram ações e serviços de esgotamento sanitário, enquanto $25,5 \%$ foram alocados para abastecimento de água.

No conjunto dos gastos com saneamento, as regiões $\mathrm{N}$ ordeste e $\mathrm{N}$ orte, principalmente a primeira, foram as mais favorecidas, absorvendo $57,2 \%$ do total de recursos. Em valores per capita, a região $\mathrm{N}$ orte com uma aplicação de $\mathrm{R} \$ 7,42$ por habitante situa-se 3,7 vezes acima da média nacional $(R \$ 1,98)$. Em seguida ficaram as regiões Centro-O este ( $R \$ 3,00)$ e Nordeste $(R \$ 2,54)$ (Tabela 5).

As diferenças interestaduais são bastante acentuadas especialmente na região $\mathrm{N}$ orte. N essa região, os val ores per capita aplicados no Acre $(R \$ 51,38)$ e em Roraima $(R \$ 73,57)$ contrastam, por exemplo, com os $\mathrm{R} \$ 0,97$ despendidos no $\mathrm{Pa}$ rá. N as demais regiões as discrepâncias entre estados, embora presentes, não têm a mesma magnitude da encontrada na região N orte. Os estados menos beneficiados foram São Paulo ( $R$ \$ $0,03)$, Rio Grande do Sul $(R \$ 0,21)$, Distrito $\mathrm{Fe}$ deral $(R \$ 0,40)$, Bahia $(R \$ 0,76)$ e Pará $(R \$ 0,97)$.

\section{- Outros gastos}

\section{a) Rede Hospitalar Federal}

M as é na distribuição dos recursos para custeio da rede hospitalar federal vinculada ao $\mathrm{M} \mathrm{i-}$ nistério da Saúde que mais claramente se estabelece o caráter concentrador histórico da oferta de serviços que tende a seguir a localização da riqueza e/ ou do poder político. Em 1999, o M inistério da Saúde gastou $R \$ 603,6$ milhões no custeio da rede vinculada, não incluindo os repasses para a rede da Fundação das Pioneiras Sociais (Sarah).

M etade dos recursos de custeio da rede federal de saúde, não incluídos os recursos provenientes da produção de serviços, são despendidos no Rio de Janeiro (per capita de $\mathrm{R} \$ 26,14$ ) (Tabela 6) onde está sediada a maior parte dos hospitais do MS (inclusive os que pertenceram à previdência social) construídos no período em que essa cidade foi capital da república. $R e$ gionalmente $96 \%$ dos recursos federais estão no Sul e Sudeste, predominantemente em duas cidades (Rio de Janeiro e Porto Alegre).

A inclusão da Rede Sarah ( $\mathrm{R} \$ 182$ milhões) poderia aumentar a desigualdade por incluir hospitais no Rio, Brasília, Belo H orizonte, Salvador e São Luiz. M as sobre as despesas da Fun- 
Tabela 5

Despesa per capi ta do M inistério da Saúde em programas selecionados, por Estado e região Em R $\$ 1,00$

\begin{tabular}{|c|c|c|c|c|c|}
\hline Região e UF & $\begin{array}{l}\text { Assistência } \\
\text { farmacêutica }\end{array}$ & $\begin{array}{l}\text { Controle } \\
\text { de endemias }\end{array}$ & $\begin{array}{l}\text { Programas } \\
\text { do FNS }\end{array}$ & $\begin{array}{l}\text { Saneamento } \\
\text { básico }\end{array}$ & Total \\
\hline Norte & 2,40 & 4,91 & 3,64 & 7,42 & 18,37 \\
\hline Rondônia & 1,61 & 7,47 & 3,84 & 9,53 & 22,45 \\
\hline Acre & 2,48 & 11,24 & 3,72 & 51,38 & 68,82 \\
\hline Amazonas & 3,23 & 5,18 & 2,76 & 4,17 & 15,34 \\
\hline Roraima & 1,80 & 16,97 & 24,53 & 73,57 & 116,87 \\
\hline Pará & 1,88 & 3,00 & 2,53 & 0,97 & 8,38 \\
\hline Amapá & 2,09 & 9,08 & 12,96 & 11,87 & 36,00 \\
\hline Tocantins & 4,33 & 3,84 & 2,67 & 8,11 & 18,95 \\
\hline Região Nordeste & 2,51 & 2,47 & 2,55 & 2,54 & 10,07 \\
\hline Maranhão & 1,14 & 2,12 & 2,02 & 2,87 & 8,15 \\
\hline Piauí & 1,89 & 2,91 & 1,88 & 1,48 & 8,16 \\
\hline Ceará & 3,84 & 2,38 & 2,17 & 3,17 & 11,56 \\
\hline Rio Grande do Norte & 3,16 & 3,97 & 3,50 & 8,86 & 19,49 \\
\hline Paraíba & 2,47 & 2,89 & 4,31 & 3,44 & 13,11 \\
\hline Pernambuco & 3,68 & 1,89 & 3,02 & 1,46 & 10,05 \\
\hline Alagoas & 2,61 & 2,99 & 2,46 & 5,48 & 13,54 \\
\hline Sergipe & 2,46 & 4,59 & 3,52 & 2,65 & 13,22 \\
\hline Bahia & 1,65 & 2,10 & 2,09 & 0,76 & 6,60 \\
\hline Região Sudeste & 7,04 & 1,39 & 2,96 & 1,01 & 12,40 \\
\hline Minas Gerais & 3,41 & 0,97 & 2,68 & 1,55 & 8,61 \\
\hline Espírito Santo & 4,26 & 1,79 & 2,17 & 8,70 & 16,92 \\
\hline Rio de Janeiro & 9,29 & 3,99 & 4,59 & 1,21 & 19,08 \\
\hline São Paulo & 8,15 & 0,55 & 2,53 & 0,03 & 11,26 \\
\hline Região Sul & 4,92 & 0,44 & 2,61 & 0,51 & 8,48 \\
\hline Paraná & 4,57 & 0,52 & 4,19 & 0,50 & 9,79 \\
\hline Santa Catarina & 5,52 & 0,41 & 1,38 & 1,11 & 8,42 \\
\hline Rio Grande do Sul & 4,93 & 0,37 & 1,74 & 0,21 & 7,25 \\
\hline Região Centro-Oeste & 3,75 & 6,88 & 4,69 & 3,00 & 18,32 \\
\hline M ato Grosso do Sul & 5,09 & 3,72 & 5,82 & 3,05 & 17,68 \\
\hline M ato Grosso & 3,27 & 4,13 & 3,47 & 8,58 & 19,45 \\
\hline Goiás & 2,47 & 2,43 & 3,28 & 1,30 & 9,48 \\
\hline Distrito Federal & 6,11 & 24,39 & 8,46 & 0,40 & 39,36 \\
\hline Brasil & 4,87 & 2,19 & 2,96 & 1,98 & 12,00 \\
\hline
\end{tabular}

Fonte : MS ( Subsecretaria de Planejamento e Orçamento); Siafi (para os dados de pessoal apurados por M aria Alice Fernandes) e Datasus. Elaboração dos autores.

dação das Pioneiras Sociais entidade não foi possível obter informação discriminada.

b) Investimentos na Rede de Saúde

Os investimentos do MS em saúde, cuja localização geográfica foi possível identificar, totalizaram em 1999 R $\$ 394$ milhões, dos quais cerca de $\mathrm{R} \$ 220$ milhões $(55,8 \%)$ corresponderam à participação do Reforsus. Este valor não incorpora, no entanto, as despesas de investimento incluídas nos repasses "fundo a fundo". A distribuição per capita favorece as regiões mais pobres, o que parece resultar do objetivo redistributivo presente nos critérios de rateio adotados pelo Reforsus. $\mathrm{N}$ as regiões Sul e Sudeste, apenas o Rio de Janeiro $(R \$ 4,14)$ está acima da média nacional $(R \$ 2,41)$, o que parece resultar do esforço na recuperação e reapareIhamento das unidades do M S sediadas na capital. Esse Estado recebeu perto de 35\% dos recursos da região. A pesar de São Paulo ter sido, em todo o país, o Estado melhor aquinhoado no montante global de recursos ( $R \$ 69,7$ milhões), o per capita correspondente ( $R \$ 1,95)$ está $19 \%$ abaixo da média nacional (Tabela 6 ). 
Tabela 6

Brasil - outras despesas per capita do M inistério da Saúde, por Estado e região 1999

Em $R \$ 1,00$

\begin{tabular}{|c|c|c|c|c|}
\hline Região e UF & Pessoal ativo & Rede MS & Investimentos FNS & Total \\
\hline Norte & 20,09 & 0,43 & 3,56 & 24,08 \\
\hline Rondônia & 35,93 & - & 3,02 & 38,95 \\
\hline Acre & 21,57 & - & 4,57 & 26,14 \\
\hline Amazonas & 15,00 & - & 3,09 & 18,09 \\
\hline Roraima & 46,45 & - & 9,11 & 55,56 \\
\hline Pará & 17,45 & 0,89 & 3,04 & 21,38 \\
\hline Amapá & 25,66 & - & 8,05 & 33,71 \\
\hline Tocantins & 18,18 & - & 4,47 & 22,65 \\
\hline Nordeste & 14,88 & 0,14 & 2,51 & 17,53 \\
\hline M aranhão & 18,85 & - & 1,48 & 20,33 \\
\hline Piauí & 12,92 & - & 2,67 & 15,59 \\
\hline Ceará & 14,88 & 0,92 & 2,31 & 18,11 \\
\hline Rio Grande do Norte & 15,40 & - & 2,84 & 18,24 \\
\hline Paraíba & 19,45 & - & 4,72 & 24,17 \\
\hline Pernambuco & 15,25 & - & 2,00 & 17,25 \\
\hline Alagoas & 14,74 & - & 2,31 & 17,05 \\
\hline Sergipe & 16,90 & - & 1,99 & 18,89 \\
\hline Bahia & 11,91 & - & 2,78 & 14,69 \\
\hline Sudeste & 16,03 & 5,17 & 2,31 & 23,51 \\
\hline M inas Gerais & 7,67 & - & 1,52 & 9,19 \\
\hline Espírito Santo & 9,93 & - & 2,78 & 12,71 \\
\hline Rio de Janeiro & 57,35 & 26,14 & 4,14 & 87,63 \\
\hline São Paulo & 4,65 & - & 1,95 & 6,60 \\
\hline Sul & 9,83 & 9,45 & 1,55 & 20,83 \\
\hline Paraná & 4,31 & - & 1,21 & 5,52 \\
\hline Santa Catarina & 7,05 & - & 1,83 & 8,88 \\
\hline Rio Grande do Sul & 16,44 & 23,16 & 1,71 & 41,31 \\
\hline Centro-Oeste & 18,50 & - & 3,21 & 21,71 \\
\hline M ato Grosso do Sul & 12,87 & - & 2,29 & 15,16 \\
\hline M ato Grosso & 10,88 & - & 3,85 & 14,73 \\
\hline Goiás & 12,19 & - & 2,72 & 14,91 \\
\hline Distrito Federal & 49,01 & - & 4,60 & 53,61 \\
\hline Brasil & 15,25 & 3,68 & 2,41 & 21,34 \\
\hline
\end{tabular}

Fonte : M S (Subsecretaria de Planejamento e Orçamento); Siafi (para os dados de pessoal apurados por M aria Alice Fernandes) e Datasus. Elaboração dos autores

As regiões $N$ orte $(R \$ 3,56)$, Centro- 0 este $(R \$ 3,21)$ e N ordeste $(R \$ 2,51)$ apresentam valores per capita acima da média nacional. $\mathrm{N}$ a região N orte essa vantagem alcança todos os estados. No N ordeste a ligeira superioridade (4\%) em relação à média nacional decorre do peso de quatro estados acima da média per capita (BA, $\mathrm{PB}, \mathrm{RN}, \mathrm{ePI}$ ), principalmente os dois primeiros, que receberam metade dos recursos da região (Tabela 6).

c) Despesas com Pessoal Ativo

A despesa com pessoal ativo do M S totalizou, em 1999, $R \$ 2,5$ bilhões - o equivalente a
$13,6 \%$ do gasto total líquido. As regiões N orte, com um per capita de $R \$ 20,09$, e Sul, com $R \$ 9,83$, são as que mais se afastam da média nacional $(R \$ 15,25)$, respectivamente, para mais e para menos.

As grandes disparidades, al gumas explicáveis, estão entre os per capita estaduais. No Estado do Rio de Janeiro o valor de $R \$ 57,35$ é de vido à localização na capital da maior parte da rede hospitalar do MS. Por outro lado, no Rio Grande Sul, o gasto per capita de $R \$ 16,44$ - 0 segundo mais al to das regiões Sudeste, Sul e Centro-O este (excluindo o DF) -, a rigor, está 
subestimado porque não incorpora as despesas com a folha de salário do Grupo Hospitalar Conceição ( $R$ \$221,7 milhões) em Porto Alegre, atendida com recursos de outra rubrica orçamentária.

Enquanto não se tem a clareza quanto aos casos de Roraima $(R \$ 46,45)$ e mesmo Rondônia $(R \$ 35,93)$, o Distrito Federal merece uma análise especial (Tabela 6). Por um lado, porque o valor encontrado - $\mathrm{R} \$ 49,01$, o segundo per capita mais al to do país - deveser visto com re servas, provavelmente, por estar contabilizando a despesa com os quadros do nível central do M S a qual, por sua natureza nacional, não deveria ser regionalizada. Por outro, o per capita está fortemente subestimado, porque como se está tratando apenas do gasto do MS, não se está incorporando a despesa do M inistério da Fazenda com o pagamento do pessoal ativo da Secretaria de Saúde local. Esse gasto, da ordem de $\mathrm{R} \$ 410$ milhões em 1999, se fosse considerado elevaria o per capita para $\mathrm{R} \$ 257,01$ incluídos os $\mathrm{R} \$ 49,01$ antes mencionados.

\section{Resultados globais}

A tabela 7 apresenta regionalizações do gasto federal com saúde considerando três agregados (a) Agregado A - somatório de recursos do MS destinados a projetos/atividades que apresentam, pelo menos teoricamente, maiores possibilidades de realocação (Assistência Ambulatorial e Hospitalar, Programas do Fundo Nacional de Saúde, M edicamentos Estratégicos e Excepcionais e Investimentos na Rede de Saúde); (b) Agregado $B$ - total dos recursos regionalizados do MS, incluindo, além dos citados no Agregado A, os recursos destinados a projetos/ atividades com maior rigidez na alocação. N este caso incluem-se as despesas com custeio da rede hospitalar própria, pessoal ativo, controle de endemias e saneamento básico; e (c) Agregado $C$ - adicionando as despesas do MEC no custeio dos hospitais universitários e de ensino e as transferências do M inistério da Fazenda para o Distrito Federal.

$\mathrm{N}$ a primeira alternativa (Agregado $A$ ), a região com maior alocação per capita $(R \$ 84,61)$ é a Sudeste, 10,2\% acima da média nacional $(R \$ 76,76) .0$ per capita da região Sul, segundo mais alto, é de $R \$ 79,12$. A variação entre a região de maior per capita (Sudeste) e de menor (Norte, $R \$ 59,78$ ) é de $24,4 \%$. N a região N ordeste o valor é de $R \$ 69,13$, segundo mais baixo do país e 18,3\% inferior ao da região Sudeste.

\section{Tabela 7}

Distribuição per capita dos recursos federais para saúde, por região e Estado, segundo diferentes agregações Em $R \$ 1,00$

\begin{tabular}{|c|c|c|c|}
\hline \multirow[t]{2}{*}{ Região e UF } & \multicolumn{3}{|c|}{ Agregados } \\
\hline & $A 1$ & B2 & $\mathrm{C}^{3}$ \\
\hline Norte & 59,78 & 92,63 & 92,75 \\
\hline Rondônia & 63,76 & 116,68 & 116,68 \\
\hline Acre & 60,71 & 144,90 & 144,90 \\
\hline Amazonas & 54,65 & 79,00 & 79,30 \\
\hline Roraima & 79,57 & 216,55 & 216,55 \\
\hline Pará & 56,63 & 78,93 & 79,06 \\
\hline Amapá & 67,31 & 113,92 & 113,92 \\
\hline Tocantins & 75,29 & 105,42 & 105,42 \\
\hline Nordeste & 69,31 & 89,35 & 89,55 \\
\hline M aranhão & 63,26 & 87,09 & 87,27 \\
\hline Piauí & 73,43 & 90,74 & 91,13 \\
\hline Ceará & 76,22 & 97,57 & 97,73 \\
\hline Rio Grande do Norte & 71,16 & 99,40 & 99,82 \\
\hline Paraíba & 69,78 & 95,56 & 95,94 \\
\hline Pernambuco & 76,20 & 94,80 & 95,04 \\
\hline Alagoas & 69,02 & 92,24 & 92,42 \\
\hline Sergipe & 69,47 & 93,61 & 93,74 \\
\hline Bahia & 62,72 & 77,49 & 77,57 \\
\hline Sudeste & 84,61 & 108,20 & 108,51 \\
\hline M inas Gerais & 70,67 & 80,85 & 81,30 \\
\hline Espírito Santo & 67,44 & 87,86 & 88,19 \\
\hline Rio de Janeiro & 88,63 & 177,33 & 177,84 \\
\hline São Paulo & 91,19 & 96,42 & 96,59 \\
\hline Sul & 79,12 & 99,35 & 103,93 \\
\hline Paraná & 81,52 & 86,85 & 87,19 \\
\hline Santa Catarina & 74,02 & 82,59 & 82,74 \\
\hline Rio Grande do Sul & 79,48 & 119,66 & 130,51 \\
\hline Centro-Oeste & 71,81 & 100,19 & 137,08 \\
\hline M ato Grosso do Sul & 70,79 & 90,42 & 90,84 \\
\hline M ato Grosso & 72,18 & 95,78 & 95,97 \\
\hline Goiás & 66,25 & 82,18 & 82,50 \\
\hline Distrito Federal & 86,06 & 159,87 & 368,53 \\
\hline Brasil & 76,76 & 99,85 & 103,26 \\
\hline
\end{tabular}

Fonte : MS (Subsecretaria de Planejamento e Orçamento);

Siafi (para os dados de pessoal apurados por M aria Alice Fernandes) e Datasus. Elaboração dos autores.

1 Inclui as despesas com assistência hospitalar e ambulatorial, programas do Fundo Nacional de Saúde, medicamentos estratégicos e excepcionais, e investimentos

2 Agregados acrescidos das despesas de custeio da rede do MS, pessoal ativo, controle de endemias e saneamento básico

${ }^{3}$ Agregado B acrescido dos gastos do M EC no custeio dos hospitais universitários e de ensino de transferências do M inistério da Fazenda para o Sistema de Saúde do Distrito Federal 
A variação percentual, positiva ou negativa, do per capita de cada Estado em relação ao per capita médio do país pode ser visto na figura 1.

A segunda alternativa (Agregado B) leva em conta todas as alocações do MS, tanto financeiras como em espécie, incluindo os dispêndios com recursos humanos e com a rede hospitalar própria concentrada no Rio de Janeiro e Porto Alegre, e não, como na anterior, apenas recursos com menor rigidez para real ocação. N esta alternativa os recursos são equivalentes a $89,2 \%$ do gasto líquido ou $80,5 \%$ do gasto total. As desigual dades inter-regionais e interestaduais se repetem nesta alternativa em proporção inferior à anterior.

A região Sudeste continua sendo a que recebe o maior valor per capita ( $R \$ 108,20)$, mas a região N ordeste passa a ser a região menos be neficiada com um per capita de $R \$ 89,35$, com uma variação de menos $17,4 \%$ em relação ao Sudeste. A alteração na colocação da região N orte deve-se ao fato de que esta alternativa inclui as despesas regionalizadas com pessoal ativo e, nessa região, por conta das atividades de controle de endemias, ainda é grande o número de servidores federais ali atuantes.

0 ordenamento dos estados e as variações percentuais dos per capita estaduais em relação ao valor médio nacional também se altera, conforme demonstrado no figura 2. Alguns estados do Norte, por força dos recursos destinados para controle de endemias, pagamento de pessoal ativo, saneamento básico e investimentos, passam a ter per capita superiores à média nacional.

A terceira alternativa (Agregado C) corresponde ao gasto federal com o SUS, ou seja, 0 gasto do M inistério da Saúde, com as exclusões mencionadas, acrescido das despesas do M EC, com H ospitais U niversitários, e do M inistério da Fazenda, com repasses para o Distrito Federal (folha de salário do pessoal ativo da Secretaria de Saúde). Com isso aumentam, ainda que ligei ramente, as disparidades entre estados, sobretudo pelo aumento dos dispêndios no Rio de Janeiro e no Distrito Federal. N ote-se que a informação sobre a rede do M EC deve ser usada com cautela, diante da provável subestimação dos dados.

\section{Alocação observada versus alocação simulada segundo critérios de necessidades}

As desigualdades na distribuição interestadual dos recursos federais apresentadas nos itens anteriores foram analisadas com base no grau de afastamento do gasto per capita de cada Estado ou região em relação ao valor médio nacional desse indicador. Contudo, em se tratando da distribuição de recursos para a saúde, uma distribuição igualitária não é necessaria-

\section{Figura 1}

Percentual em relação a média per capita dos recursos federais para a saúde, por unidades da federação, segundo agregado " $A$ ".

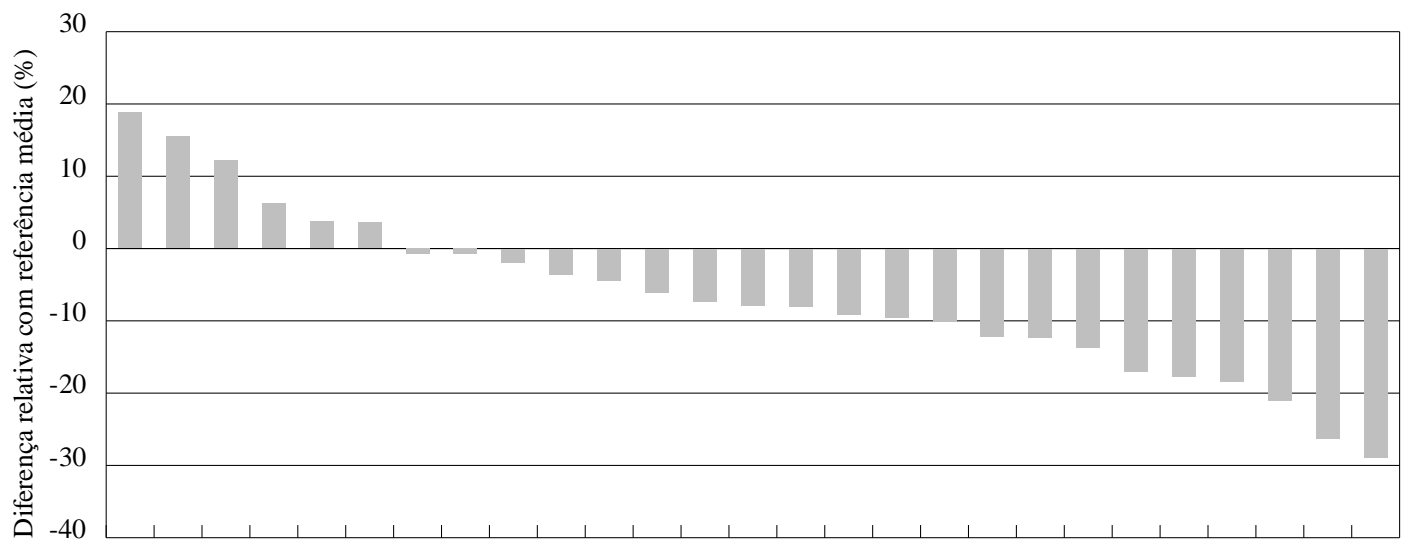

SP RJ DF PR RR RS CE PE TO SC PI MT RN MS MG PB SE AL ES AP GO RO MA BA AC PA AM Unidades da Federação 
Figura 2

Percentual em relação a média per capita dos recursos federais para a saúde, por unidades da federação, segundo agregado " $B$ ".

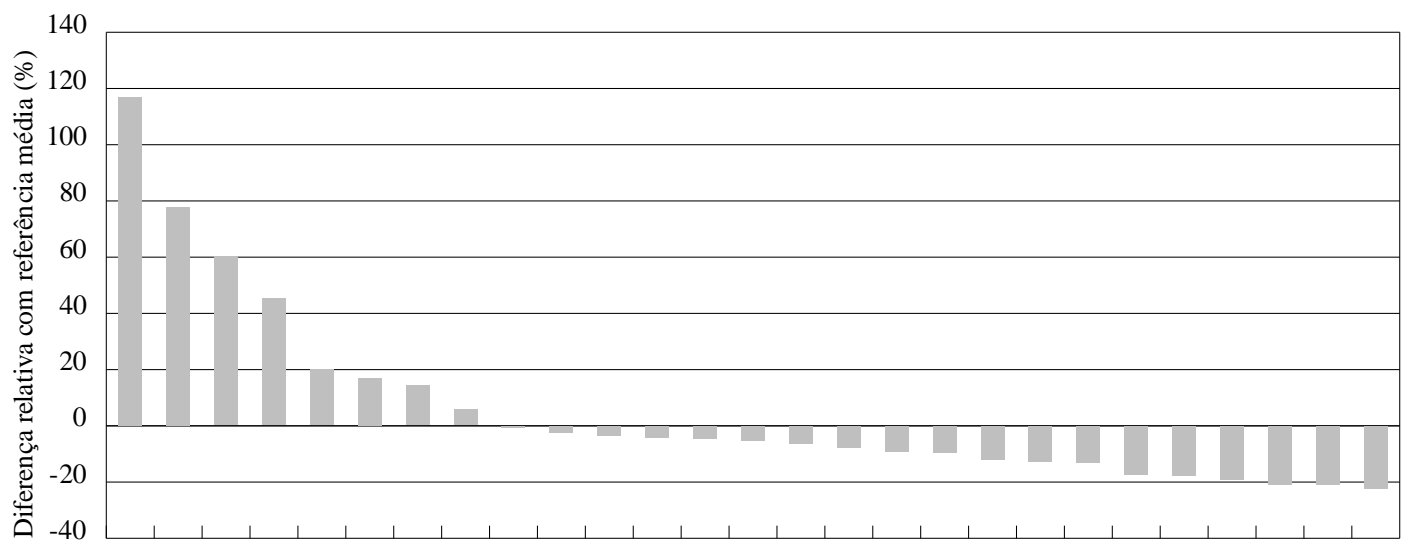

RR RJ DF AC RS RO AP TO RN CE SP MT PB PE SE AL PI MS ES MA PR SC GO MG AM PA BA Unidades daFederação

mente eqüitativa, sobretudo se forem levadas em consideração as diferenças nos perfis demográfico, epidemiológico e socioeconômico da população, que determinam diferentes níveis de necessidades de saúde. Dessa forma, um ponto fundamental nas diferentes abordagens metodológicas para estimar uma distribuição eqüitativa dos recursos para a saúde deve necessariamente incorporar as desigual dades no perfil demográfico, segundo sexo e idade, e um indicador de necessidades, que permita dimensionar desigualdades relativas entre condições sanitárias e socioeconômicas das populações de distintas áreas geográficas.

U ma metodologia para a alocação de recursos com base nas necessidades de saúde, baseada em experiências internacionais, em especial a inglesa, foi desenvolvida por Porto et al. (2001). No referido estudo foi construída uma fórmula para a alocação de recursos, incorporando as dimensões supramencionadas. Como proxy de necessidades de saúde criou-se um indicador composto, a partir de doze variáveis epidemiológicas e socioeconômicas, por meio de um procedimento de análise estatística multivariada (análise dos componentes principais).

A comparação entre a distribuição observada dos recursos federais para a assistência ambulatorial e hospitalar em 1999 e aquela estimada segundo critérios de necessidades de saúde (Tabela 8) demonstra que, para se ter uma distribuição mais eqüitativa:
1) as regiões N orte e N ordeste deveriam ter um acréscimo de mais de $17 \%$ no per capita médio e todos os estados dessas duas regiões seriam beneficiados com aumentos nos respectivos per capita que variariam entre 7,71\% (Tocantins) e 30,99\% (Pernambuco);

2) todos os estados das regiões Sudeste e Sul, com exceção do Espírito Santo, sofreriam al guma redução no gasto por habitante. As mais importantes ocorreriam nos estados de São Paulo (-19,32\%), Paraná (-10,83\%) e Rio Grande do Sul $(-10,68)$. As duas regiões perderiam entre 10 a $11 \%$ na distribuição segundo as necessidades de saúde;

3) a região Centro-O este manteria, aproximadamente, a mesma distribuição per capita; entretanto, os três estados ganhariam mais recursos, enquanto o Distrito Federal perderia $13,21 \%$ no seu per capita.

Cabe destacar que nesta comparação não estão incluídas todas as despesas efetuadas pelo M inistério da Saúde com assistência ambulatorial e hospitalar, já que não foram considerados os recursos destinados à rede própria e a "organizações sociais", como por exemplo a rede Sarah Kubitschek, por serem menos passíveis de redistribuições inter-regionais. Contudo, para avaliar o impacto mais completo da alocação estimada em função de indicadores de necessidades, esses recursos deveriam ser incluídos. Da mesma forma, a fórmula aplicada sobre o montante total da despesa regionalizada do M inis- 
Tabela 8

M S: Distribuição observada dos gastos per capita em assistência hospitalar e ambulatorial do M inistério da Saúde e alocação per capita estimada segundo população ajustada por sexo/idade/custo e proxy de necessidade, Brasil, 1999. Em $R \$ 1,00$

\begin{tabular}{|c|c|c|c|}
\hline \multirow{2}{*}{$\begin{array}{l}\text { Região / UF } \\
\text { Estado }\end{array}$} & \multicolumn{3}{|c|}{ Gasto per capita com Assistência Ambulatorial e H ospitalar (1) } \\
\hline & Observado & Estimado & Diferença \\
\hline Norte & 51.52 & 69.08 & 17.56 \\
\hline Rondônia & 56.35 & 66.11 & 9.76 \\
\hline Acre & 51.43 & 73.90 & 22.47 \\
\hline Amazonas & 46.98 & 64.77 & 17.79 \\
\hline Roraima & 45.49 & 70.02 & 24.53 \\
\hline Pará & 50.40 & 71.10 & 20.70 \\
\hline Amapá & 46.40 & 58.73 & 12.33 \\
\hline Tocantins & 65.49 & 73.20 & 7.71 \\
\hline Nordeste & 62.58 & 80.03 & 17.45 \\
\hline Maranhão & 59.57 & 84.50 & 24.93 \\
\hline Piauí & 67.58 & 83.82 & 16.24 \\
\hline Ceará & 68.98 & 78.12 & 9.14 \\
\hline Rio Grande do Norte & 62.54 & 79.66 & 17.12 \\
\hline Paraíba & 58.77 & 89.76 & 30.99 \\
\hline Pernambuco & 68.24 & 78.79 & 10.55 \\
\hline Alagoas & 62.41 & 92.26 & 29.85 \\
\hline Sergipe & 62.74 & 71.94 & 9.20 \\
\hline Bahia & 56.97 & 75.17 & 18.20 \\
\hline Sudeste & 73.43 & 62.32 & -11.11 \\
\hline M inas Gerais & 63.89 & 62.85 & -1.04 \\
\hline Espírito Santo & 59.13 & 61.85 & 2.72 \\
\hline Rio de Janeiro & 71.49 & 66.01 & -5.48 \\
\hline São Paulo & 79.99 & 60.67 & -19.32 \\
\hline Sul & 71.00 & 60.81 & -10.19 \\
\hline Paraná & 72.53 & 61.70 & -10.83 \\
\hline Santa Catarina & 66.31 & 58.26 & -8.05 \\
\hline Rio Grande do Sul & 71.96 & 61.28 & -10.68 \\
\hline Centro-Oeste & 61.52 & 61.99 & 0.47 \\
\hline M ato Grosso do Sul & 58.63 & 63.00 & 4.37 \\
\hline M ato Grosso & 62.95 & 63.99 & 1.04 \\
\hline Goiás & 59.15 & 63.25 & 4.10 \\
\hline Distrito Federal & 68.61 & 55.40 & -13.21 \\
\hline Brasil & 67.58 & 67.58 & 0.00 \\
\hline
\end{tabular}

(1) Assistência hospitalar/ambulatorial inclui pagamentos do $\mathrm{SIH} / \mathrm{SIA}$,

Transferências para M AC e Atendimentos Básicos 
tério da Saúde, por ter esta uma distribuiç̧ão observada diferente daquela da assistência ambulatorial e hospitalar, daria resultados diferentes em termos de variações para mais ou para menos dos per capita estaduais.

\section{Considerações finais}

É inegável o avanço do processo de descentralização da gestão para estados e municípios. N essa trajetória, privilegiou-se critérios e mecanismos distintos de transferências, segundo o tipo de serviço ou programa, ao invés da idéia original de repasses globais. Na política alocativa do M inistério da Saúde a eqüidade na distribuição dos recursos foi pouco valorizada, ainda que a expansão de algumas ações, especialmente as de atenção básica, tenham favorecido, indubitavelmente, as regiões e os segmentos populacionais com maiores necessidades de saúde.

0 conhecimento da distribuição dos recursos federais entre os diferentes estados e regiões do país é um dos requisitos essenciais para avaliação do impacto redistributivo da participação federal no financiamento do SUS, bem como para balizar propostas de novos critérios alocativos que tenham o alcance de maior eqüidade na distribuição dos recursos como principal objetivo.

A regionalização observada dos recursos do M inistério da Saúde em 1999 nas três alternativas analisadas (Agregados A, B e C) demonstra que a distribuição dos recursos federais apresentou partilhas inter-regionais e interestaduais que favorecem as regiões e, com raras exceções, os estados mais desenvolvidos.

Separadamente, o custeio da rede própria do $\mathrm{MS} \mathrm{e} 0$ atendimento ambulatorial de média e alta complexidade, por exemplo, apresentam distribuições per capita que favorecem, nitidamente, as regiões mais desenvolvidas do Sudeste, Sul e Centro-O este.

Por outro lado, os investimentos do M S em infra-estrutura da rede de saúde, a assistência farmacêutica, atenção básica, controle de ende- mias e saneamento, parecem ser, embora determinados por critérios distintos, os que mais tendem à eqüidade.

Cabe lembrar que a regionalização aqui apresentada teve por objeto somente os recursos federais. Seguramente as desigualdades seriam bem maiores se fosse analisada a alocação do gasto público total com saúde, incluindo, nesse caso, as despesas dos estados e municípios com recursos próprios. Em princípio, os estados e municípios mais ricos devem aplicar mais em saúde.

Contudo, como dito anteriormente, a simples medição dos diferenciais dos per capita estaduais em relação à média nacional não é suficiente para medir as iniqüidades na alocação de recursos. A utilização de fórmula alocativa que contempla os diferentes perfis demográfico, epidemiológico e as condições sócio-sanitárias de cada Estado mostra, no exemplo anteriormente apresentado, a existência de iniqüidades na alocação dos recursos para assistência ambulatorial e hospitalar. Caso os recursos financeiros fossem alocados a partir da fórmula que contempla as dimensões supra-referidas, deveria haver uma redistribuição de recursos da maior parte dos estados das regiões Sudeste e Sul e do Distrito Federal em favor dos estados das regiões $N$ orte e N ordeste.

N aturalmente, o processo de alocação eqüitativa dos recursos para custeio deve ser acompanhado de programas de investimento que tenham por objetivo equilibrar inter-regionalmente a oferta de serviços de saúde. Ademais, uma política de diminuição do grau de iniqüidades existente na alocação dos recursos federais deve ser implementada de forma gradual e continuada, preferentemente com recursos adicionais, o que reduzi ria as resistências políticas à sua implementação.

Por último, é preciso salientar que a adoção de critérios de eqüidade no estabelecimento de tetos estaduais deveria ser acompanhada por políticas similares no âmbito estadual, pois, sem isso, corre-se o risco de pouco contribuir para a diminuição das desigualdades inter-municipais. 


\section{Referências bibliográficas}

Brasil 2002. Relatório de gestão da Secretaria da Assistência à Saúde 1998/2001. (2a, ed. revista e modificada). M inistério da Saúde, Secretaria de Assistência à Saúde. Brasília.

Brasil 1997. Constituição da República Federativa do Brasil. Promulgada em 5 de outubro de 1988. Saraiva, São Paulo.

Brasil 1995. Avaliação do funcionamento dos Conselhos Estaduais e M unicipais de Saúde. M inistério da Saúde.

Brasil 1997. M inistério da Saúde. Lei n. 8.080/90. Lei Orgânica da Saúde - 1990. M anual de Gestor SUS. Lidador, Rio de Janeiro.

Brasil 1997. M inistério da Saúde. N orma O peracional Básica SU S 01/1993 - Portaria M S n. 545, 20 de maio de 1993. M anual de Gestor SUS. Lidador, Rio de Janeiro.

Levcovitz E, Lima L \& M achado C 2001. Política de saúde nos anos 90: relações intergovernamentais e o papel das N ormas O peracionais Básicas. Revista Ciência e Saúde Coletiva 6(2):269-291.
M édici AC 1991. Perspectivas do financiamento à saúde no governo Collor de M ello. OPAS (Série Economia e Financiamento, n. 2).

Porto SM \& U gá M AD 1992. Avanços e percalços do financiamento do setor saúde no Brasil. In E Gallo et al. (orgs.). Planejamento criativo: novos desafios teóricos em políticas de saúde. Relume-Dumará, Rio de Janeiro.

Rezende F 1992. 0 financiamento da saúde no marco das propostas de reforma do Estado e do sistema tributário brasileiro. OPAS (Série Economia e Financiamento, n. 3).

U gá M AD 1991. Descentralização e democracia: o outro lado da moeda. Revista Planejamento e Políticas Públicas 5, jun. I pea.

U gá M AD 1997. Proposta de reforma do setor saúde nos marcos do ajuste macroeconômico. Tese de doutoramento, UERJ. (M imeo).

Artigo apresentado em 15/10/2002

Aprovado em 18/10/2002

Versão final apresentada em 4/11/2002 